\title{
Correlation between ventricular function as assessed by echocardiography and six-minute walk test as a surrogate of functional capacity in patients with chronic obstructive pulmonary disease
}

\author{
Magdy M. Khalil ${ }^{a}$, Hala M. Salem ${ }^{a}$, Hossam-Eldin M. Abdil-Hamid ${ }^{a}$, \\ Muhammad Y. Zakaria ${ }^{\mathrm{b}}$
}

Background Exercise intolerance is common in patients with chronic obstructive pulmonary disease (COPD), which has multiple mechanisms underlying its progression. Ventricular dysfunction may play a role in the development of exercise incapacity in patients with COPD.

Aim To investigate the possible contribution of left ventricular (LV) and right ventricular (RV) dysfunction (either systolic or diastolic) in development of exercise intolerance in patients with COPD.

Patients and methods A total of 60 patients with diagnosis of COPD were categorized according to GOLD spirometric stage into two groups (group 1: mild to moderate COPD, and group 2: severe to very severe COPD). Both groups were evaluated by spirometry, ECG, chest radiography, routine laboratory investigation, 6-min walk test, and echocardiography including tissue Doppler imaging

Results The average age in the whole study group was 56.63 \pm 10.33 years. Male patients in the study were $46(76.7 \%)$ and female patients were 14 (23.3\%). Mean maximum walk distance among the whole group was $342.75 \pm 54.85 \mathrm{~m}$. There was a significant correlation between 6-min walk distance and transtricuspid $\mathrm{E}$ velocity, tricuspid $\mathrm{E} / \mathrm{A}$, and transtricuspid deceleration time $(P=0.011,0.015$, and 0.021 , respectively). There was no significant correlation between 6-min walk

\section{Introduction}

Chronic obstructive pulmonary disease (COPD) is on its way to be the third most common killer disease worldwide by $2020[1,2]$. Although being of primary pulmonary origin, it has a unique physiological and pathophysiological characteristics that may cause extrapulmonary effects and comorbidities [3-5]. Comorbidities are associated with high mortality, reduced compliance to medications, and diminished quality of life [6]. Cardiovascular comorbidities are among the most frequently seen comorbidities associated with COPD [4,7]. Many studies have demonstrated a strong association between heart failure and COPD [8-10].

Exercise intolerance is common in patients with COPD, which has multiple mechanisms underlying its progression. Increased ventilatory demand, associated with altered dynamic mechanics, abnormal gas exchange, airway limitation, and peripheral muscle dysfunction, is among the intrinsic distance and parameters of LV diastolic dysfunction. Prevalence of ventricular dysfunction was as follow: LV systolic dysfunction $3.3 \%$, LV diastolic dysfunction $30 \%$, RV systolic dysfunction $21 \%$, and RV diastolic dysfunction $46 \%$.

Conclusion RV diastolic dysfunction may be a contributing factor in the progression of exercise intolerance in COPD. Although LV diastolic dysfunction may not be associated with exercise intolerance, it is still prevalent in COPD and must be assessed and managed through the course of the disease and especially during exacerbation.

Egypt J Bronchol 2019 13:459-468

(C) 2019 Egyptian Journal of Bronchology

Egyptian Journal of Bronchology 2019 13:459-468

Keywords: 6-min walk test, chronic obstructive pulmonary disease, echocardiography, exercise intolerance, ventricular dysfunction

${ }^{a}$ Department of Chest Diseases, Faculty of Medicine, Ain Shams University,

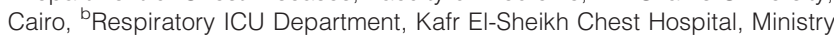
of Health, Kafr El-Sheikh, Egypt

Correspondence to Muhammad Y. Zakaria, MSc, Borg El-Burrulos, Kafr ElSheikh, Egypt. Tel: +20 122251 1538;

e-mail: yhya_762@yahoo.com

Received: 29 May 2019 Revised: 6 August 2019

Accepted: 9 September 2019 Published: 25 October 2019

pulmonary mechanisms that are alleged for exercise incapacity seen in such patients [11-15]. There is increasing evidence that ventricular dysfunction may play a role in development of exercise intolerance in patients with COPD.

In the present study, we tried to assess the left ventricular (LV) and right ventricular (RV) function either systolic or diastolic in patients with COPD. We tried to correlate echocardiographic parameters of ventricular function with 6-min walk test as a surrogate for exercise capacity to reveal any contribution of ventricular function on exercise intolerance found in patients with COPD.

This is an open access journal, and articles are distributed under the terms of the Creative Commons Attribution-NonCommercial-ShareAlike 4.0 License, which allows others to remix, tweak, and build upon the work non-commercially, as long as appropriate credit is given and the new creations are licensed under the identical terms. 


\section{Patients and methods}

The protocol of the study was approved by Research Ethics Committee REC, Ain Shams University (FMASU MD 196/2016). The study included 60 patients. Inclusion criteria entailed sure diagnosis of COPD (presence of risk factors, clinical symptoms and signs, radiology, and spirometry) among patients who were admitted to inpatient and outpatient clinic in Kafr El-Sheikh Chest Hospital in the period from December 2016 to July 2018. Exclusion criteria were the presence of severe liver or kidney disease, presence of recent or old ischemic heart disease or other valvular heart disease, severe systemic hypertension, pulmonary disease other than COPD, acute venous thromboembolism, hemoglobin less than $10 \mathrm{~g} / \mathrm{dl}$, patients who cannot perform spirometry or 6-min walk test, and patients with acute exacerbation of COPD. After taking a written and informed consent from all patients participating in the study, patients were categorized according to GOLD spirometric criteria into group 1 (mild to moderate COPD, forced expiratory volume in $1 \mathrm{~s}$ (FEV1)/forced vital capacity $<70 \%$, and FEV1 $>50 \%$ ) and group 2 (severe to very severe COPD, FEV1/forced vital capacity $<70 \%$, and FEV1<50\%). Routine laboratory investigations to exclude severe liver or kidney diseases were performed. Chest radiography to ensure hyperinflation and rule out any other chest diseases and ECG to exclude ischemic changes or arrhythmias were done. Six-min walk test was performed according to ATS guidelines for all participants [16]. Patients were instructed to walk through a corridor of 30-m length as fast as they can for $6 \mathrm{~min}$. Theywere encouraged by simple words throughout the test and were instructed to stop immediately if they feel they cannot complete the test or if any complications occurred. The outcome of the test was recorded as the maximum distance the patient walked, the basal and post-test heart rate, the basal and post-test oxygen saturation, and complication during the test (if occurred). Echocardiography was done for all patients in the cardiology department, EL-Obour Insurance Hospital, using General Electric (GE) machine, VIVID S5, with a transducer (probe), 3S-RS 1.5-3.6 MHz. Images were acquired according to the latest guidelines [17,18] (Fig. 1) and revised by two cardiologists in the department.

Linear LV dimension was taken from parasternal longaxis PLAX at the end of diastole, and ejection fraction (by Teicholtz method) and fractional shortening were derived. Transmitral flow was assessed using E, A, E/ $\mathrm{A}$, and deceleration time. Then tissue Doppler imaging (TDI) modality was used to measure e', and E/e' was calculated.
RV linear dimensions were obtained in apical fourchamber view. Tricuspid annular plane excursion (TAPSE) was measured by 2D modality, and then transtricuspid flow was assessed similar to transmitral flow using E, A, E/A, and deceleration time. TDI was used to measure myocardial peak tricuspid annular velocity (S') and E', and then E/E' was calculated.

LV systolic dysfunction was present when EF is less than 50\%. LV diastolic dysfunction was present when two of the following criteria are present [19]: (a) lateral e' velocity less than $10 \mathrm{~m} / \mathrm{s}(0.10 \mathrm{~m} / \mathrm{s})$, (b) E/e' more than 14 , and (c) tricuspid regurgitant velocity more than $2.8 \mathrm{~m} / \mathrm{s}$.

RV systolic dysfunction was present when TAPSE less than $1.6 \mathrm{~cm}$ or $S^{\prime}$ less than $10 \mathrm{~cm} / \mathrm{s}(0.10 \mathrm{~m} / \mathrm{s})$. RV diastolic dysfunction was present when one of the following was present: (a) $\mathrm{E} / \mathrm{A}<0.8$, (b) $\mathrm{E} / \mathrm{A}$ from 0.8 to 2.1 and $\mathrm{E} / \mathrm{E}^{\prime}>6$, and (c) E/A more than 2.1 and deceleration time less than $120 \mathrm{~ms}$.

The collected data were revised, coded, tabulated, and introduced to a PC using Statistical package for Social Science (SPSS 25; IBM SPSS version 25, Chicago, Illinois, USA). Data were presented, and suitable analysis was done according to the type of data obtained for each parameter. Student $t$ test and Mann-Whitney test ( $U$ test) were used to assess the statistical significance of the difference of parametric and nonparametric variables (respectively) between two study groups. $\chi^{2}$ test and Fisher's exact test were used to examine the relationship between two qualitative variables according to their number. Correlation analysis (using Pearson's method) was used to assess the strength of association between two quantitative variables.

\section{Results}

Table 1 summarizes patients data, comorbidities, laboratory investigations, arterial blood gases, spirometry, and 6-min walk test. Male patients in the study were $46(76.7 \%)$ and female patients were 14 (23.3\%). Both groups included 23 (76.67\%) males and seven (23.33\%) females. Dyspnea was the most frequent complaint. Most patients were current smokers (46.7\%) or ex-smokers (30.0\%). Systemic arterial hypertension was the most common comorbidity (21\%). One patient had hypothyroidism and liver cirrhosis, and an another one had hypertension and HCV. Normal sinus rhythm with no ischemia was the most common finding in ECG, and all patients showed signs of hyperinflated chest on 


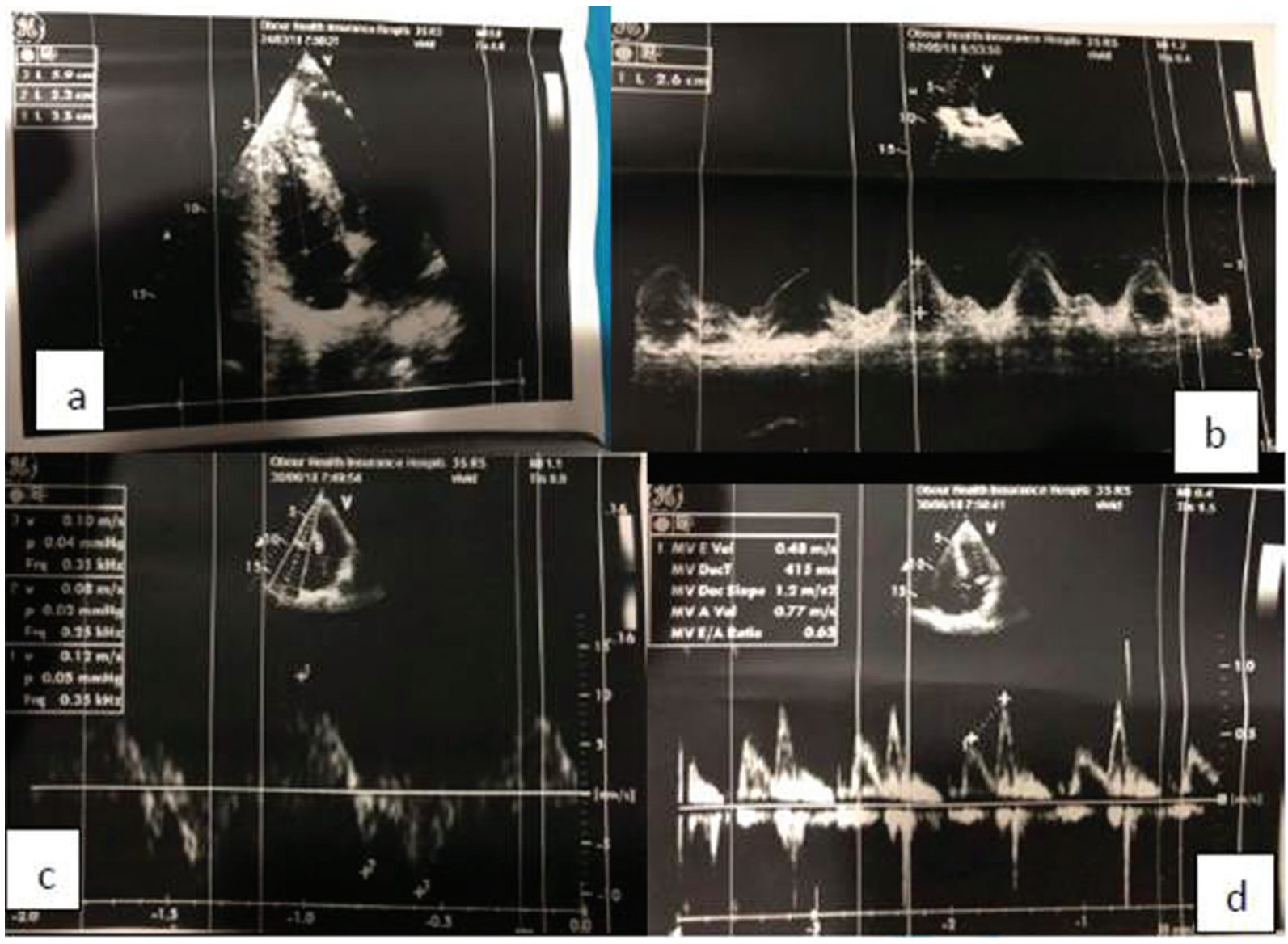

(a) Linear dimensions of right ventricle: basal diameter, mid cavity, and longitudinal. (b) TAPSE by applying M-mode at the lateral free wall of RV. (c) Myocardium velocities by TDI at the lateral tricuspid annulus: $1 \rightarrow S^{\prime}, 2 \rightarrow$ E'. (d) Transmitral flow parameters: E, A, and E/A. RV, right ventricular; TAPSE, tricuspid annular plane excursion; TDI, tissue Doppler imaging.

plain chest radiography. Mean \pm SD maximum walk distance among the whole group was 342.75 $\pm 54.85 \mathrm{~m}$, mean $\pm \mathrm{SD}$ maximum walk distance was $373.33 \pm 41.86 \mathrm{~m}$ in group $\mathrm{A}$ and $312.17 \pm 49.32 \mathrm{~m}$ in group B. Mean LV and RV echocardiographic parameters representative of both systolic and diastolic functions are summarized in Table 2.

\section{Correlation between 6-min walk test and ventricular function}

There was a significant positive correlation between 6min walk distance and ejection fraction of the $\mathrm{LV}$ among the whole study group. There was no significant correlation between 6-min walk distance and other parameters of $\mathrm{LV}$ diastolic dysfunction. Regarding the RV, there was a significant correlation between 6-min walk distance and transtricuspid E velocity (Fig. 2), tricuspid E/A (Fig. 3), and transtricuspid deceleration time (Fig. 4) $(P=0.011,0.015$, and 0.021 , respectively). These are parameters of RV diastolic dysfunction. There was a significant correlation between 6-min walk distance and TAPSE (parameter indicative of systolic function) in mild to moderate COPD. In patients with severe to very severe $\mathrm{COPD}$, there was a significant correlation between 6-min walk distance and RV E/A (Fig. 5).

\section{Prevalence of ventricular systolic and diastolic dysfunction in patients with chronic obstructive pulmonary disease}

LV systolic dysfunction was present in 3.3\% of study population (Table 3). There was no significant difference between both groups. LV diastolic dysfunction occurred in 18 (30\%) patients. Among these 18 patients, grade 1 diastolic dysfunction (impaired relaxation) was present in 15 (25\%) patients and grade 2 diastolic dysfunction (pseudonormal filling) was present in three (5\%) patients.

RV systolic dysfunction occurred in 13 (21.7\%) patients. There was no significant difference between both groups. $\mathrm{RV}$ diastolic dysfunction occurred in 28 (46.7\%) patients. Among these 28 patients, grade 1 diastolic dysfunction (impaired relaxation) was present in 14 (23.3\%) patients, grade 2 diastolic dysfunction (psuedonormal filling) was present in $11(18.3 \%)$ patients and grade 3 diastolic dysfunction (restrictive filling) was present in three 
Table 1 Patients data, laboratory investigations, arterial blood gas, pulmonary function test, and 6-min walk test results

\begin{tabular}{|c|c|c|c|c|c|}
\hline & All patients & Group 1 & Group 2 & $P$ value & Significance \\
\hline Age & $56.63 \pm 10.33$ & $51.63 \pm 11.16$ & $61.63 \pm 6.38$ & $<0.001$ & S \\
\hline Male & $46(76.7)$ & 23 (76.67) & $23(76.67)$ & & \\
\hline Female & $14(23.3)$ & 7 (23.33) & 7 (23.33) & & \\
\hline Height (cm) & $166.82 \pm 8.23$ & $167.8 \pm 7.34$ & $165.83 \pm 9.06$ & 0.359 & NS \\
\hline Weight (kg) & $71.55 \pm 9.15$ & $71.63 \pm 8.1$ & $71.47 \pm 10.22$ & 0.944 & NS \\
\hline No smoke & $14(23.3)$ & 7 (23.33) & 7 (23.33) & & \\
\hline Smoking & $28(46.7)$ & $15(50)$ & 13 (43.33) & & \\
\hline Ex-smoking & $18(30.0)$ & $8(26.67)$ & $10(33.33)$ & & \\
\hline No comorbidities & $41(68.3)$ & $23(76.67)$ & $18(60)$ & & \\
\hline $\mathrm{HTN}$ & $13(21.6)$ & $4(13.3)$ & $9(30)$ & & \\
\hline DM & 2 (3.3) & $1(3.33)$ & $1(3.33)$ & & \\
\hline CVS & $1(1.7)$ & $1(3.33)$ & 0 & & \\
\hline Old TB & $1(1.7)$ & 0 & $1(3.33)$ & & \\
\hline Hypothyroidism & $1(1.7)$ & 0 & $1(3.33)$ & & \\
\hline HCV (treated) & $1(1.7)$ & $1(3.33)$ & 0 & & \\
\hline Liver cirrhosis & $2(3.3)$ & $2(6.6)$ & 0 & & \\
\hline Systolic BP & $119.17 \pm 12.39$ & $116.67 \pm 12.41$ & $121.67 \pm 12.06$ & 0.119 & NS \\
\hline Diastolic BP & $78.25 \pm 7.91$ & $77.5 \pm 7.51$ & $79 \pm 8.35$ & 0.467 & NS \\
\hline Basal heart rate & $83.08 \pm 9.69$ & $81.27 \pm 10.63$ & $84.9 \pm 8.44$ & 0.148 & NS \\
\hline CBC (Hb) (g/dl) & $13.10 \pm 1.37$ & $13.29 \pm 1.42$ & $12.91 \pm 1.31$ & 0.286 & NS \\
\hline CBC $\left(\right.$ TLC $\left.\times 10^{3}\right)$ & $8.51 \pm 3.51$ & $8.41 \pm 3.79$ & $8.61 \pm 3.27$ & 0.825 & NS \\
\hline $\mathrm{pH}$ & $7.40 \pm 0.04$ & $7.4 \pm 0.04$ & $7.39 \pm 0.05$ & 0.335 & NS \\
\hline $\mathrm{PO}_{2}$ (on roam air) & $65.0 \pm 7.0$ & $68.8 \pm 6.5$ & $60.37 \pm 4.93$ & $<0.001$ & S \\
\hline $\mathrm{PCO}_{2}$ & $43.0 \pm 6.0$ & $41.47 \pm 5.74$ & $45.33 \pm 6.04$ & 0.014 & S \\
\hline FEV1 (I) & $1.41 \pm 0.58$ & $1.85 \pm 0.39$ & $0.97 \pm 0.33$ & $<0.001$ & S \\
\hline FEV1 of predicted & $46.33 \pm 16.10 \%$ & $60.27 \pm 6.55 \%$ & $32.4 \pm 9.09 \%$ & $<0.001$ & S \\
\hline FVC (I) & $2.35 \pm 0.93$ & $3.07 \pm 0.67$ & $1.63 \pm 0.49$ & $<0.001$ & S \\
\hline FEV1/FVC & $60.70 \pm 6.67 \%$ & $60.53 \pm 7.09 \%$ & $60.87 \pm 6.33 \%$ & 0.848 & NS \\
\hline Maximum walk distance (m) & $342.75 \pm 54.85$ & $373.33 \pm 41.86$ & $312.17 \pm 49.32$ & $<0.001$ & S \\
\hline Basal $\mathrm{SPO}_{2}$ & $92.33 \pm 2.52 \%$ & $93.2 \pm 2.38 \%$ & $91.47 \pm 2.39 \%$ & 0.007 & S \\
\hline Post-test $\mathrm{SPO}_{2}$ & $90.40 \pm 3.22 \%$ & $91.87 \pm 2.75 \%$ & $88.93 \pm 3.02 \%$ & $<0.001$ & S \\
\hline Post-test heart rate & $89.62 \pm 12.58$ & $85.13 \pm 9$ & $94.1 \pm 14.13$ & 0.005 & S \\
\hline
\end{tabular}

The mean and SD of demographic data, comorbidities, signs and symptoms, laboratory investigations, and outcome of 6-min walk test among the whole study group and comparison between both study groups. BP, blood pressure; CBC, complete blood count; DM, diabetes mellitus; FEV1, forced expiratory volume in 1 s; FVC, forced vital capacity; Hb, hemoglobin; HTN, hypertension; S, significance; TLC, total leukocyte count.

(5\%) patients. There was a significant difference between both groups, with an increased prevalence of diastolic dysfunction among severe and very severe COPD. Prevalence of RV diastolic dysfunction in this group reached 76\%, which supports the accumulating evidence of the importance of RV pathology in the course of the disease.

\section{Discussion}

The main findings in the present study are the high prevalence of $\mathrm{RV}$ and $\mathrm{LV}$ diastolic dysfunction in patients with COPD, and the presence of significant correlation between RV diastolic dysfunction and 6min walk test, implying a contribution of $\mathrm{RV}$ diastolic dysfunction on exercise incapacity.

In the present study, we found no significant correlation between 6-min walk distance and other parameters of
LV diastolic dysfunction. In contrast with our study, López-Sánchez et al. [20] found a significant correlation between decreased 6-min walk distance and E/A, indicating contribution of $\mathrm{LV}$ diastolic dysfunction in patients' exercise intolerance. One of the limitations of their study is the exclusion of mild to moderate COPD and very severe COPD. They only included patients with severe COPD, which may explain this difference in results. Fenster et al. [21] did not found this association between LV diastolic dysfunction and 6min walk distance reported by López-Sánchez et al.. Another study by Schoos et al. [22] did not find a correlation between LV diastolic dysfunction and 6min walk distance. Another recent study by Muller et al. [23] compared patients with COPD having LV diastolic dysfunction with patients having no diastolic dysfunction using cardiopulmonary exercise test. They found no association between LV diastolic dysfunction and worsening of exercise tolerance. 


\begin{tabular}{|c|c|c|c|c|c|}
\hline & All patients & Group 1 & Group 2 & $P$ value & Significance \\
\hline \multicolumn{6}{|l|}{ Left ventricle } \\
\hline LVEDD (cm) & $4.73 \pm 0.85$ & $4.71 \pm 0.8$ & $4.76 \pm 0.91$ & 0.822 & NS \\
\hline LVESD (cm) & $3.19 \pm 0.66$ & $3.15 \pm 0.52$ & $3.23 \pm 0.78$ & 0.641 & NS \\
\hline IVS (cm) & $1.21 \pm 0.21$ & $1.17 \pm 0.18$ & $1.25 \pm 0.23$ & 0.14 & NS \\
\hline $\mathrm{PW}(\mathrm{cm})$ & $1.28 \pm 0.28$ & $1.22 \pm 0.28$ & $1.34 \pm 0.28$ & 0.103 & NS \\
\hline EF & $60.75 \pm 7.45 \%$ & $61.3 \pm 6.23 \%$ & $60.2 \pm 8.56 \%$ & 0.572 & NS \\
\hline$E(m / s)$ & $0.58 \pm 0.14$ & $0.59 \pm 0.15$ & $0.57 \pm 0.13$ & 0.465 & NS \\
\hline$A(m / s)$ & $0.63 \pm 0.17$ & $0.62 \pm 0.17$ & $0.65 \pm 0.18$ & 0.469 & NS \\
\hline $\mathrm{E} / \mathrm{A}$ & $0.97 \pm 0.30$ & $1.0 \pm 0.26$ & $0.95 \pm 0.34$ & 0.529 & NS \\
\hline$E^{\prime}(m / s)$ & $0.10 \pm 0.03$ & $0.11 \pm 0.04$ & $0.09 \pm 0.02$ & 0.046 & S \\
\hline $\mathrm{E} / \mathrm{e}^{\prime}$ & $6.30 \pm 2.22$ & $6.07 \pm 2.46$ & $6.54 \pm 1.97$ & 0.411 & NS \\
\hline FS & $33.10 \pm 5.69 \%$ & $33.43 \pm 4.84$ & $32.77 \pm 6.5$ & 0.654 & NS \\
\hline Deceleration time (ms) & $218.53 \pm 59.96$ & $234.07 \pm 56.12$ & $203 \pm 60.55$ & 0.044 & $S$ \\
\hline \multicolumn{6}{|l|}{ Right ventricle } \\
\hline RV basal diameter $(\mathrm{cm})$ & $3.60 \pm 0.47$ & $3.6 \pm 0.45$ & $3.59 \pm 0.5$ & 0.914 & NS \\
\hline RV mid diameter (cm) & $2.81 \pm 0.47$ & $2.84 \pm 0.48$ & $2.78 \pm 0.48$ & 0.648 & NS \\
\hline RV long. diameter (cm) & $6.46 \pm 0.88$ & $6.5 \pm 0.74$ & $6.42 \pm 1.01$ & 0.707 & NS \\
\hline TAPSE $(\mathrm{cm})$ & $2.06 \pm 0.35$ & $2.1 \pm 0.34$ & $2.03 \pm 0.36$ & 0.422 & NS \\
\hline \multicolumn{6}{|l|}{ S' (peak velocity) } \\
\hline Lat. annulus) (m/s) & $0.14 \pm 0.06$ & $0.13 \pm 0.03$ & $0.15 \pm 0.09$ & 0.291 & NS \\
\hline $\mathrm{RV} E(\mathrm{~m} / \mathrm{s})$ & $0.53 \pm 0.11$ & $0.55 \pm 0.08$ & $0.51 \pm 0.13$ & 0.245 & NS \\
\hline $\mathrm{RV} A(\mathrm{~m} / \mathrm{s})$ & $0.55 \pm 0.19$ & $0.52 \pm 0.11$ & $0.58 \pm 0.25$ & 0.246 & NS \\
\hline $\mathrm{RV} E / \mathrm{A}$ & $1.07 \pm 0.35$ & $1.09 \pm 0.26$ & $1.04 \pm 0.43$ & 0.589 & NS \\
\hline $\mathrm{E} / \mathrm{E}^{\prime}$ & $5.36 \pm 1.91$ & $5.21 \pm 1.52$ & $5.52 \pm 2.25$ & 0.532 & NS \\
\hline RV decel. time (ms) & $200.55 \pm 45.72$ & $211.6 \pm 39.12$ & $189.5 \pm 49.69$ & 0.061 & NS \\
\hline TR reg. velocity $(\mathrm{m} / \mathrm{s})$ & $1.71 \pm 0.88$ & $1.41(0.99-1.9)$ & 1.66 (1.03-2.57) & $0.211(\mathrm{M})$ & NS \\
\hline sPAP by $(\mathrm{mmHg})$ & $20.09 \pm 16.90$ & $12(9.09-19.44)$ & $16.01(9.24-31.41)$ & $0.22(\mathrm{M})$ & NS \\
\hline
\end{tabular}

Mean echocardiographic parameters in the whole study group and compares between both study groups. EF, ejection fraction; FS, fractional shortening; IVS, interventricular septum (IVS) thickness; Lt vent A, transmitral A wave velocity; Lt vent e', lateral mitral annulus e' wave velocity by tissue Doppler; Lt vent. E, transmitral E wave velocity; LVEDD, left ventricle end diastolic dimension; LVESD, left ventricle end systolic dimension; PW, posterior wall thickness; RV A, transtricusped A wave velocity; RV E, transtricusped E wave velocity; S', right ventricle free wall velocity at tricuspid lateral annulus by tissue Doppler imaging; sPAP, estimated pulmonary artery pressure; TAPSE, tricuspid annular plane systolic excursion.

Watz et al. [24] estimated Pro-BNP as a marker of myocardial failure and correlated it with 6-min walk test. They concluded that physical activity is associated with LV diastolic dysfunction. Pro-BNP is not specific for LV pathologies and may be increased in RV dysfunction. Patients with LV dysfunction may also have RV dysfunction, which causes the observed exercise intolerance.

Regarding the RV, there was a significant correlation between 6-min walk distance and parameters of RV diastolic dysfunction. This positive correlation among the whole study group suggests a decreased exercise capacity in presence of $\mathrm{RV}$ diastolic dysfunction irrespective of COPD spirometric stage, which may suggest that even in mild and moderate airflow limitation, when RV diastolic dysfunction develops, exercise incapacity may evolve.

The role of ventricular dysfunction in progression of exercise intolerance in COPD was not fully determined. Furthermore, the RV was always neglected in traditional workup and studies to the extent that it was once coined as 'the forgotten chamber' [25]. The present study supports the results of Fenster et al. [21], who studied the correlation between 6-min walk test and RV diastolic function. They found a positive significant correlation between 6-min walk distance and RV E/A. They concluded that $\mathrm{RV}$ diastolic dysfunction may contribute to exercise intolerance in patients with COPD [21]. They referred the association between RV diastolic dysfunction and decreased exercise tolerance to diminished RV preload and stroke volume, which may be exacerbated during exercise [21]. Although Schoos et al. [22] did not find this association between lower 6-min walk distance and $\mathrm{RV}$ diastolic dysfunction, they reported a reduction in $\mathrm{RV}$ diastolic function parameters. In addition, they excluded mild COPD and very severe COPD, which may affect the overall correlation. Cuttica et al. [26], in their study of patients without severely impaired lung function, demonstrated that structural changes of the right heart are associated with a decrement in 6-min walk distance independent of spirometric stage. However, 


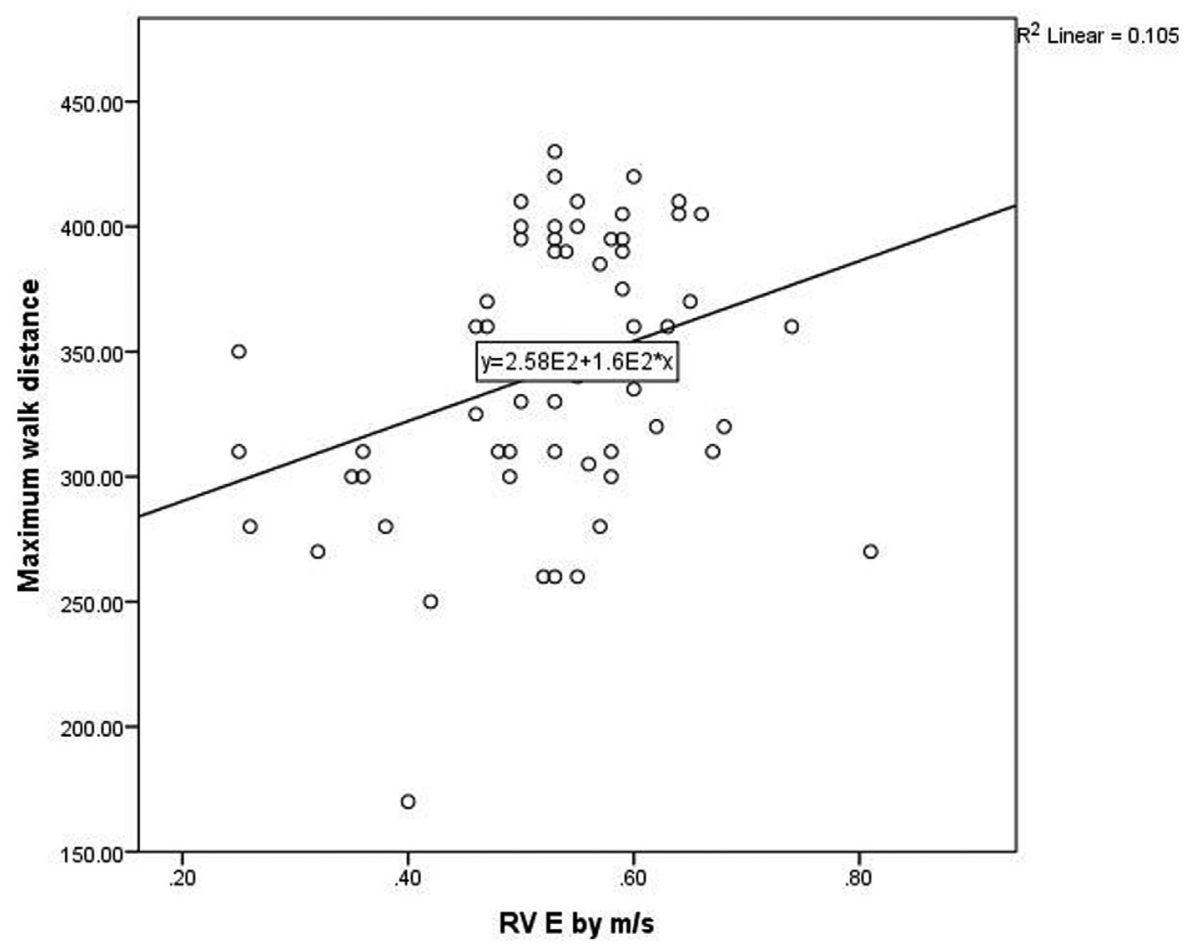

Correlation between 6-min walk distance and RV transtricuspid E velocity. A lower 6-min walk distance is associated with lower E velocity among the whole study group. RV, right ventricular.

Figure 3

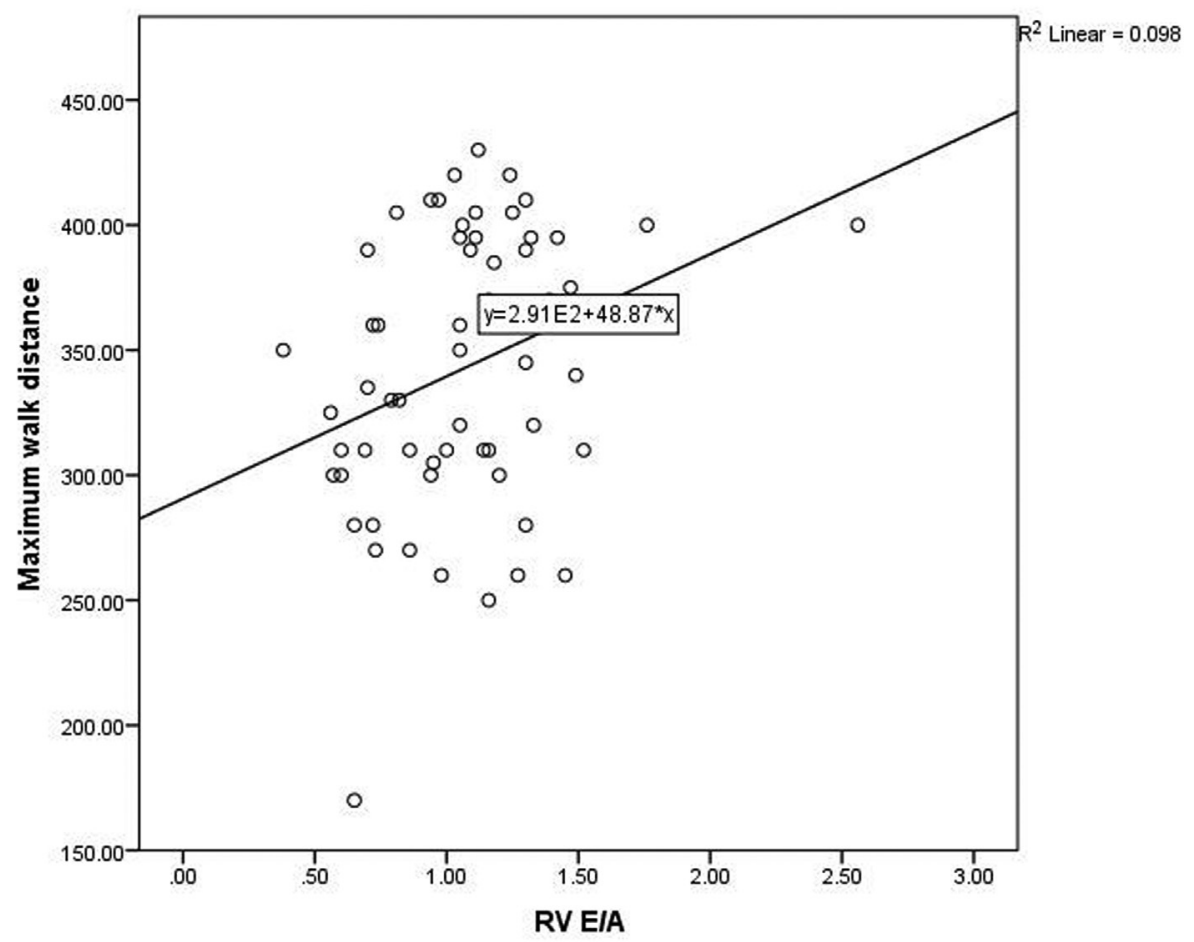

Correlation between 6-min walk distance and right ventricular E/A in the whole study group. A lower 6-min walk distance is associated with lower E/A ratio.

they did not find an association between 6-min walk distance and RV systolic function as assessed by TAPSE or LV systolic or diastolic function [26].
Although our study did not include control group, there is a large body of evidence that LV dysfunction is prevalent in patients with COPD 


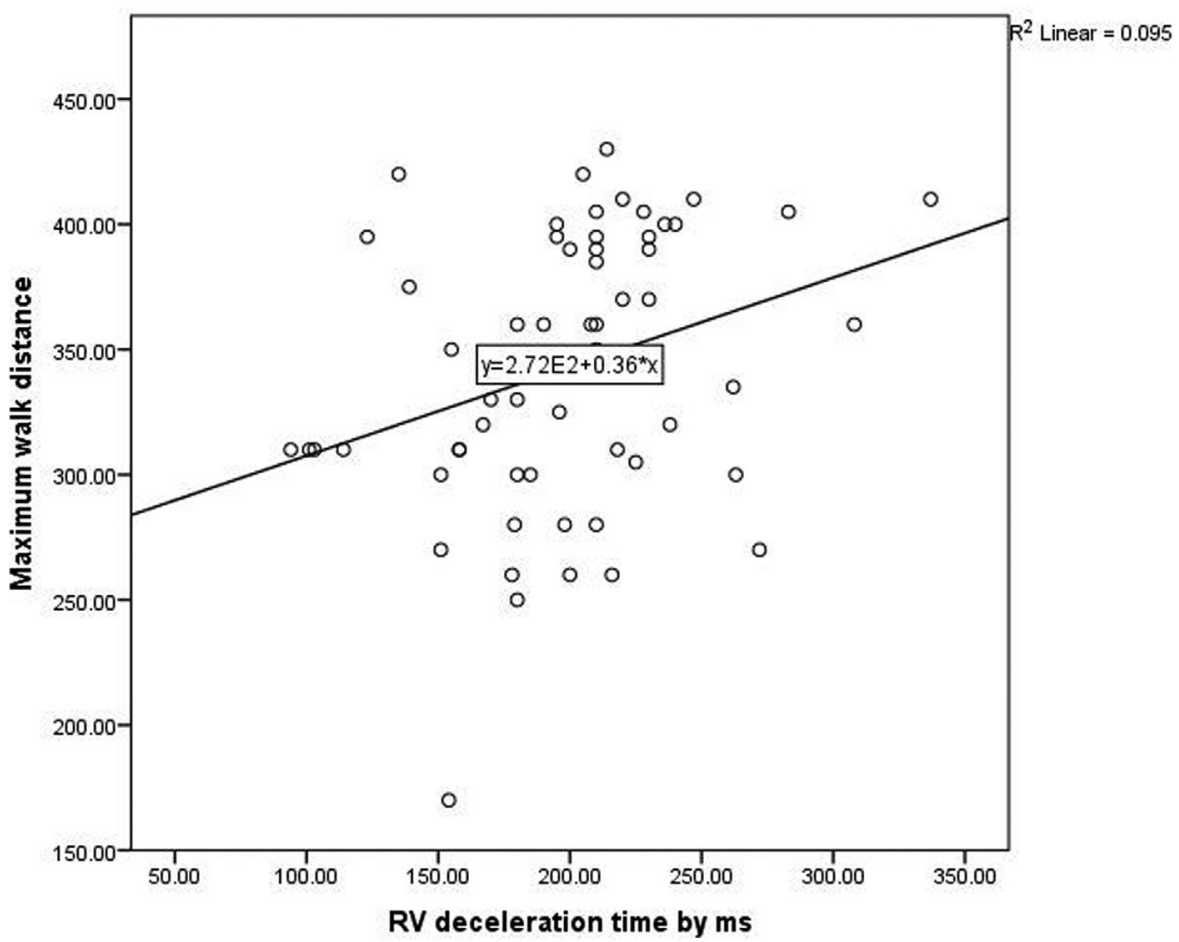

Correlation between 6-min walk distance and right ventricular deceleration time in the whole study group. A lower 6-min walk distance is associated with lower deceleration time.

Figure 5

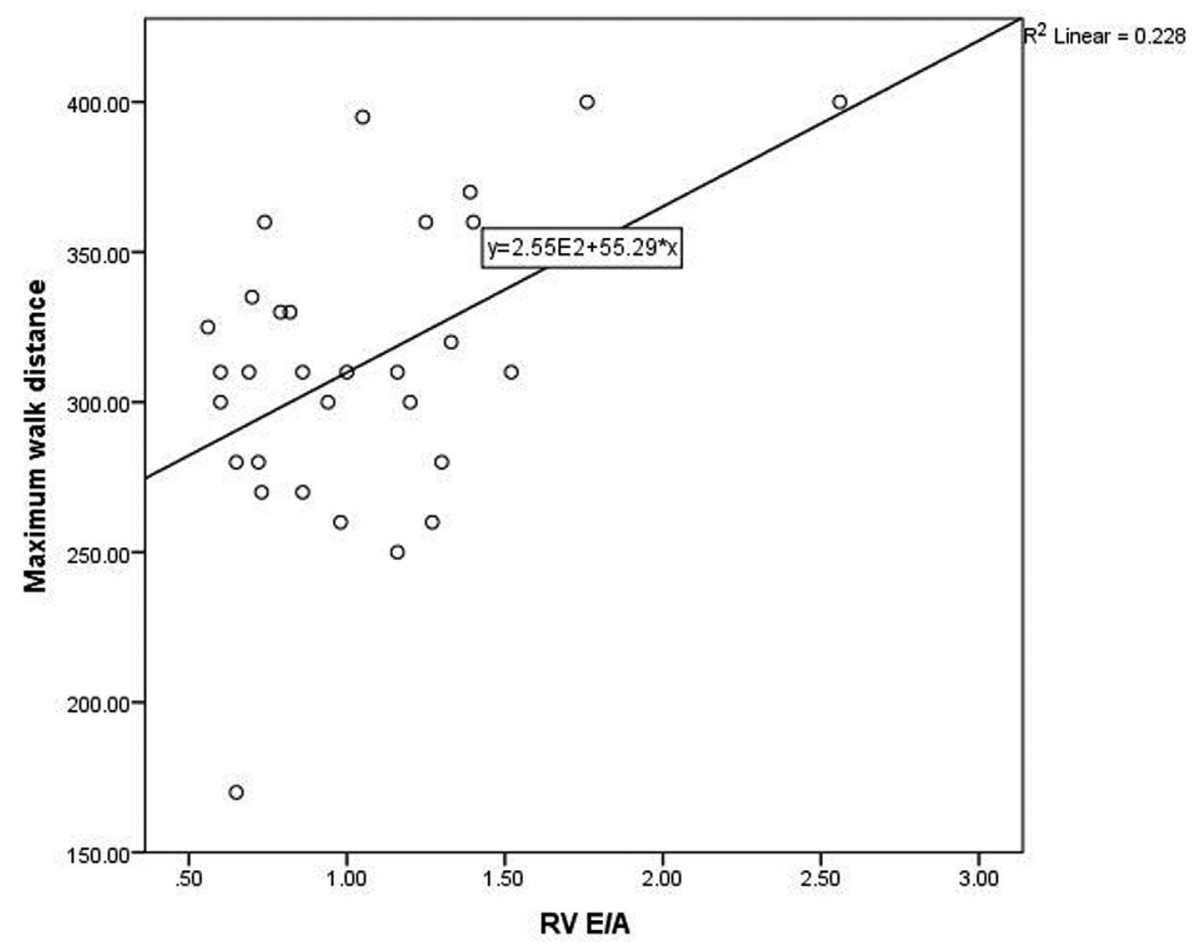

Correlation between 6-min walk distance and transtricuspid E/A in group B. A lower 6-min walk distance is correlated with a lower E/A in patients with severe to very severe COPD. COPD, chronic obstructive pulmonary disease.

[20,27-31]. Prevalence of LV diastolic dysfunction varies largely between different studies. Our estimate is relatively close to another study by Gupta et al. [27] who reported a prevalence of $47.5 \%$ among their study group which include 40 patients with COPD of different spirometric stages. Another recent study by 
Table 3 Prevalence and grades of left and right ventricular dysfunction

\begin{tabular}{|c|c|c|c|c|c|}
\hline & All patients & Group 1 & Group 2 & $P$ value & Significance \\
\hline LV systolic dysfunction & $2(3.3)$ & $1(3.33)$ & 1 (3.33) & $1.00(\mathrm{~F})$ & NS \\
\hline LV diastolic dysfunction & $18(30.0)$ & $6(20)$ & $12(40)$ & $0.091(\mathrm{C})$ & NS \\
\hline Grade 1 & $15(25.0)$ & $6(20)$ & $9(30)$ & 0.141 & NS \\
\hline Grade 2 & $3(5.0)$ & 0 & $3(10)$ & & \\
\hline RV systolic dysfunction & $13(21.0)$ & $4(13.33)$ & $9(30)$ & $0.117(\mathrm{C})$ & NS \\
\hline RV diastolic dysfunction: & $28(46.7)$ & $7(23.33)$ & $21(70)$ & $<0.001(\mathrm{C})$ & $S$ \\
\hline (a) Grade 1 & $14(23.3)$ & $4(13.33)$ & $10(33.33)$ & & \\
\hline (b) Grade 2 & $11(18.3)$ & $3(10)$ & $8(26.67)$ & 0.002 & S \\
\hline (c) Grade 3 & $3(5)$ & 0 & $3(10)$ & & \\
\hline
\end{tabular}

This table represents the prevalenc of systolic and diastolic dysfunction of the the left and right heart among the whole study group and in both study groups. LV, left ventricular; RV, right ventricular; S, significance.

Jatav et al. [28] estimated LV diastolic dysfunction to be $46 \%$ in a sample of 100 patients with COPD. This is in contrary to a study performed by Miranda et al. [29] who reported a prevalence of $\mathrm{LV}$ diastolic dysfunction of $88 \%$ among their study group and also observed a significant difference between both groups of study (group 1: mild to moderate COPD and group 2: severe to very severe COPD). López-Sánchez et al. [20] found LV diastolic dysfunction in 90\% of their group (80\% grade 1 and $10 \%$ grade 2). Rawy and Fathalla [30] reported a prevalence of $73.3 \%$. However, many authors argue that, Freixa et al. reported a prevalence of $12 \%$ in COPD patients on their first hospital admissions [31]. But actually Freixa and colleagues found diastolic dysfunction in about $60 \%$ of their study sample but were exposed to error in data summarization and reporting.

This difference in the prevalence of diastolic dysfunction may be owing to variability in echocardiographic parameters needed to diagnose and grade diastolic dysfunction. One of the contributions of the present study is the utilization of the most recent algorism suggested by the American Society of Echocardiography published in 2016 for diagnosis and grading of LV diastolic dysfunction in our patients' diagnosis and grading. Systemic hypertension and cardiac ischemia are the most common causes of diastolic dysfunction. Another contribution of the present study is the exclusion of patients with a prior history of ischemic heart diseases, and patients with severe arterial hypertension who may not be excluded in some other studies [29].

In the present study, RV systolic dysfunction occurred in $13(21.7 \%)$ patients. There was no significant difference between both groups. In the previously mentioned study by Jatav et al. [28], RV systolic dysfunction was present in $14 \%$ of patients. In the study by Gupta et al. [27], RV systolic dysfunction was present in $7.5 \%$ of patients. In their study, RV systolic dysfunction was diagnosed by eyeballing when observing wall motion hypokinesia. Obviously, this method may underestimate the presence of impaired function in many patients. Vizza et al. [32] estimated the prevalence of $\mathrm{RV}$ systolic dysfunction (defined by $\mathrm{RV}$ ejection fraction $<45 \%$ ) in patients with COPD as $59 \%$. An advantage of using TDI to assess RV function is that measurement is independent of geometric assumptions and endocardial border tracing. Another strength of the present study is the incorporation of TDI parameters like peak tricuspid lateral annulus velocity ( $\left.S^{\prime}\right)$ in assessment of $R V$ systolic function evaluation.

Importantly, RV dysfunction either systolic or diastolic was formerly linked to development of pulmonary hypertension. The increased pulmonary vascular resistance with subsequent increase in $\mathrm{RV}$ afterload will lead to RV hypertrophy, and then dilation and even RV failure. Recent studies have demonstrated that RV dysfunction may occur even in the absence of pulmonary hypertension. They referred RV changes to other mechanisms such as systemic inflammation, microvascular ischemia, hypoxia, systemic hypertension and obesity [21,33-37]. Hilde et al. [38] concluded a similar observation about the presence of $\mathrm{RV}$ function changes in absence of pulmonary hypertension in patients with COPD. From a clinical point of view, exercise training is proved to enhance exercise capacity and quality of life in patients with heart failure with preserved ejection fraction $[39,40]$ which is frequently caused by RV dysfunction [41-44] or LV diastolic dysfunction [45]. Owing to the high prevalence of RV systolic and diastolic dysfunction and LV diastolic dysfunction in our patients with COPD, exercise training should be prescribed in patients with COPD having these ventricular abnormalities. Moreover, avoiding tachycardia by correcting hypoxemia and optimizing medication is mandatory to maintain LV filling [46]. It is not clear whether phosphodiesterase inhibitors 
(PDE 5) - which is proved to improve RV function [47] - enhance RV function by direct mechanism or by improving RV afterload [21]. So, the role of PDE 5 in RV diastolic dysfunction in patients with COPD should be evaluated. Again, LV diastolic dysfunction and RV dysfunction should be assessed and managed promptly in every COPD exacerbation as they may be the cause of cardiac decompensation responsible for this exacerbation [48].

\section{Limitations}

The study was cross-sectional, so firm conclusions about causality cannot be made. Moreover, we did not have a control group, so we used reference values from literature. Performing echocardiography was difficult in patients with COPD because of the limited acoustic window owing to hyperinflation; however, only measurements with a satisfactory image quality have been used for analyses.

In conclusion, RV diastolic dysfunction may be a contributing factor in progression of exercise intolerance in COPD regardless of patients' spirometric stage. Although LV diastolic dysfunction may not be associated with exercise intolerance, it is still prevalent in COPD and must be assessed and managed through the course of the disease and especially during exacerbation.

\section{Acknowledgements}

The authors thank professor Muhammad Kamal Salama, $\mathrm{MD}$, professor of cardiology, Aswan University, for his great help and consultation in this study. The authors also thank their colleagues, Dr Mahmoud Nasr, Dr Emad ElGammal, Dr Hamada Abdul-Baset, and Dr Asmaa Barakat, cardiologists in Cardiology Department, ElObour Hospital, for their great help and assistance in performing echocardiography for their patients. Moreover, the authors thank Dr Eslam Saboukh, a lecturer of cardiology, Kafr El-Sheikh University, for his great help and advice.

\section{Financial support and sponsorship \\ Nil.}

\section{Conflicts of interest}

There are no conflicts of interest.

\section{References}

1 Global Initiative For Chronic Obstructive (GOLD). The global strategy for diagnosis, management and prevention of COPD; 2018. Available at: https://goldcopd.org/wp-content/uploads/2017/11/GOLD-2018-v6.0FINAL-revised-20-Nov_WMS.pdf. [Accessed at 2019 Mar 6].
2 Lozano R, Naghavi M, Foreman K, Lim S, Shibuya K, Aboyans V, et al. Global and regional mortality from 235 causes of death for 20 age groups in 1990 and 2010: a systematic analysis for the Global Burden of Disease Study 2010. Lancet 2012;380:2095-2128.

3 Yin $\mathrm{H}$, Yin S, Lin Q, Xu Y, Xu H, Liu T. Prevalence of comorbidities in chronic obstructive pulmonary disease patients: a meta-analysis. Medicine 2017; 96:1-6.

4 Brown JP, Martinez $\mathrm{CH}$. Chronic obstructive pulmonary disease comorbidities. Curr Opin Pulm Med 2016; 22:113-118.

5 Chatila WM, Thomashow BM, Minai OA, Criner GJ, Make BJ. Comorbidities in chronic obstructive pulmonary disease. Proc $\mathrm{Am}$ Thorac Soc 2008; 5:549-555.

6 Hillas G, Perlikos F, Tsiligianni I, Tzanakis N. Managing comorbidities in COPD. Int J Chron Obstruct Pulmon Dis 2015; 10:95.

7 Huiart L, Ernst P, Suissa S. Cardiovascular Morbidity and Mortality in COPD. Chest 2005; 128:2640-2646.

8 Chetty U, Mclean G, Morrison D, Agur K, Guthrie B. Chronic obstructive pulmonary disease and comorbidities: a large cross-sectional study in primary care. Br J Gen Pract 2017; 67:e321-e328.

9 De Miguel DJ, García TG, Maestu LP. Comorbidities in COPD. Arch Bronconeumol 2010; 46:20.

10 Cavaille A, Gut-gobert C, Marchand-adam S, Meurice J, Morel H, Persontacnet C. Comorbidities of COPD. Eur Respir Rev 2013; 22:454-475.

11 O'Donnell DE, Elbehairy AF, Domnik NJ, Vincent S, Guenette JA, Webb $\mathrm{KA}$, et al. Patterns of cardiopulmonary response to exercise in COPD. In Palange P, Laveneziana P, Neder JA, et al., editors. Clinical exercise testing (ERS monograph). Sheffield: European Respiratory Society; 2018. 107.

12 O'donnell DE, D'arsigny C, Fitzpatrick M, Webb KA. Exercise hypercapnia in advanced chronic obstructive pulmonary disease: the role of lung hyperinflation. Am J Respir Crit Care Med 2002; 166:663-668.

13 Marin JM, Carrizo SJ, Gascon M, Sanchez A, Gallego B, Celli BR. Inspiratory capacity, dynamic hyperinflation, breathlessness, and exercise performance during the 6-minute-walk test in chronic obstructive pulmonary disease. Am J Respir Crit Care Med 2001 163:1395-1399.

14 Caviedes IR, Delgado I, Soto R. Ventilatory inefficiency as a limiting factor for exercise in patients with COPD. Respir Care 2012; 57:583-589.

15 Gosselink R, Troosters T, Decramer M. Peripheral muscle weakness contributes to exercise limitation in COPD. Am J Respir Crit Care Med 1996; 153:976-980.

16 Crapo RO, Casaburi R, Coates AL, Enright PL, MaCintyre NR, Mckay RT, et al. ATS statement: guidelines for the six-minute walk test. Am J Respir Crit Care Med 2002; 166:111-117.

17 Rudski LG, Lai WW, Afilalo J, Hua L, Handschumacher MD, Chandrasekaran $\mathrm{K}$, et al. Guidelines for the echocardiographic assessment of the right heart in adults: a report from the American Society of Echocardiography endorsed by the European Association of Echocardiography, a registered branch of the European Society of Cardiology, and the Canadian Society of Echocardiography. J Am Soc Echocardiogr 2010; 23:685-713.

18 Lang RM, Badano LP, Mor-avi V, Afilalo J, Armstrong A, Ernande L, et al. Recommendations for cardiac chamber quantification by echocardiography in adults: an update from the American Society of Echocardiography and the European Association of Cardiovascular Imaging. J Am Soc Echocardiogr 2015; 28:1-39.

19 Nagueh SF, Smiseth OA, Appleton CP, Byrd BF, Dokainish H, Edvardsen $\mathrm{T}$, et al. Recommendations for the evaluation of left ventricular diastolic function by echocardiography: an update from the American Society of Echocardiography and the European Association of Cardiovascular Imaging. Eur J Echocardiogr 2016; 17:1321-1360.

20 López-Sánchez M, Muñoz-esquerre M, Huertas D, Gonzalez-costello J, Manresa F, Dorca J, et al. High prevalence of left ventricle diastolic dysfunction in severe copd associated with a low exercise capacity: a cross-sectional study. PloS One 2013; 8:2-9.

21 Fenster BE, Holm KE, Weinberger HD, Moreau KL, Meschede K, Crapo $\mathrm{JD}$, et al. Right ventricular diastolic function and exercise capacity in COPD. Respir Med 2015; 109:1287-1292.

22 Schoos MM, Dalsgaard M, Kjærgaard J, Moesby D, Jensen SG, Steffensen I, et al. Echocardiographic predictors of exercise capacity and mortality in chronic obstructive pulmonary disease. BMC CardiovasC Disord 2013; 13:84.

23 Muller PT, Utida KAM, Augusto TRL, Spreafico MVP, Mustafa RC, Xavier $A W$, et al. Left ventricular diastolic dysfunction and exertional ventilatory inefficiency in COPD. Respir Med 2018; 145:101-109. 
24 Watz H, Waschki B, Boehme C, Claussen M, Meyer T, Magnussen $\mathrm{H}$. Extrapulmonary Effects of chronic obstructive pulmonary disease on physical activity a cross-sectional study. Am J Respir Crit Care Med 2008; 177:743-751.

25 Rigolin VH, Robiolio PA, Wilson JS, Harrison JK, Bashore TM. The forgotten chamber: the importance of the right ventricle. Cathet Cardiovasc Diagn 1995; 35:18-28.

26 Cuttica MJ, Shah SJ, Rosenberg SR, Orr R, Beussink L, Jane E, et al. Right heart structural changes are independently associated with exercise capacity in non-severe COPD. PLoS One 2011; 6:e29069.

27 Gupta NK, Agrawal RK, Srivastav AB, Ved ML. Echocardiographic evaluation of heart in chronic obstructive pulmonary disease patient and its co-relation with the severity of disease. Lung India 2011; 28:105.

28 Jatav VS, Meena SR, Jelia S, Jain P, Ajmera D, Agarwal V, et al. Echocardiographic findings in chronic obstructive pulmonary disease and correlation of right ventricular dysfunction with disease severity. IJAM 2017; 4:476-480.

29 Miranda L, Caram DO, Ferrari R, Naves CR, Tanni SE, Sousa L, et al. Association between left ventricular diastolic dysfunction and severity of chronic obstructive pulmonary disease. Clinics 2013; 68:772-776.

30 Rawy AM, Fathalla D. Left ventricular diastolic dysfunction in patients with chronic obstructive pulmonary disease (COPD), prevalence and association with disease severity: Using tissue Doppler study. Egypt $J$ Chest Dis Tuberc 2015; 64:785-792.

31 Freixa X, Portillo K, Paré C, Garcia-Aymerich J, Gomez FP, Benet M, et al. Echocardiographic abnormalities in patients with COPD at their first hospital admission. Eur Respir J 2013; 41:784-791.

32 Vizza CD, Lynch JP, Ochoa LL, Richardson G, Trulock EP. Right and left ventricular dysfunction in patients with severe pulmonary disease. Chest 1998; 113:576-583.

33 Huez S, Faoro V, Guénard H, Martinot JB, Naeije R. Echocardiographic and tissue Doppler imaging of cardiac adaptation to high altitude in native highlanders versus acclimatized lowlanders. Am J Cardiol 2009; 103:1605-1609.

34 Huez S, Roufosse F, Vachiéry JL, Pavelescu A, Derumeaux G, Wautrecht $\mathrm{JC}$, et al. Isolated right ventricular dysfunction in systemic sclerosis: latent pulmonary hypertension? Eur Respir J 2007; 30:928-936.

35 Cicala S, Galderisi M, Caso P, Petrocelli A, D'Errico A, De Divitiis O, et al. Right ventricular diastolic dysfunction in arterial systemic hypertension: analysis by pulsed tissue Doppler. Eur J Echocardiogr 2002; 3:135-142.

36 Rawat DK, Alzoubi A, Gupte R, Chettimada S, Watanabe M, Kahn AG, et al. Increased reactive oxygen species, metabolic maladaptation, and autophagy contribute to pulmonary arterial hypertension-induced ventricular hypertrophy and diastolic heart failure. Hypertension 2014; 64:1266-1274.
37 Zhuiko A, Gertcen M, Atroschenko E. Right ventricular diastolic function in patients with COPD and heart failure, depending on endothelial function. Eur Respir J 2013; 42:2496.

38 Hilde JM, Skjørten I, Grøtta J, Hansteen V, Melsom MN, Hisdal J, et al. Right ventricular dysfunction and remodeling in chronic obstructive pulmonary disease without pulmonary hypertension. J Am Coll Cardiol 2013; 62:1103-1111.

39 Kitzman DW, Brubaker PH, Herrington DM, Morgan TM, Stewart KP, Hundley WG, et al. Effect of endurance exercise training on endothelial function and arterial stiffness in older patients with heart failure and preserved ejection fraction: a randomized, controlled, singleblind trial. J Am Coll Cardiol 2013; 62:584-592.

40 Edelmann F, Gelbrich G, Düngen HD, Fröhling S, Wachter R, Stahrenberg $\mathrm{R}$, et al. Exercise training improves exercise capacity and diastolic function in patients with heart failure with preserved ejection fraction: results of the Ex-DHF (Exercise training in Diastolic Heart Failure) pilot study. J Am Coll Cardiol 2011; 58:1780-1791.

41 Melenovsky V, Hwang SJ, Lin G, Redfield MM, Borlaug BA. Right heart dysfunction in heart failure with preserved ejection fraction. Eur Heart $J$ 2014; 35:3452-3462.

42 Mohammed SF, Hussain I, AbouEzzeddine OF, Takahama H, Kwon SH, Forfia $\mathrm{P}$, et al. Right ventricular function in heart failure with preserved ejection fraction: a community-based study. Circulation 2014; 130:2310-2320.

43 Gorter TM, Hoendermis ES, van Veldhuisen DJ, Voors AA, Lam CSP, Geelhoed B, et al. Right ventricular dysfunction in heart failure with preserved ejection fraction: a systematic review and meta-analysis. Eur $\checkmark$ Heart Fail 2016; 18:1472-1487.

44 Puwanant S, Priester TC, Mookadam F, Bruce CJ, Redfield MM, Chandrasekaran K. Right ventricular function in patients with preserved and reduced ejection fraction heart failure. Eur J Echocardiogr 2009; 10:733-737.

45 Kane GC, Karon BL, Mahoney DW, Redfield MM, Roger VL, Burnett JC, et al. Progression of left ventricular diastolic dysfunction and risk of heart failure. JAMA 2011; 306:856-863.

46 Boussuges A, Pinet $\mathrm{C}$, Molenat $\mathrm{F}$, Burnet $\mathrm{H}$, Ambrosi $\mathrm{P}$, Badier $\mathrm{M}$, et al. Left atrial and ventricular filling in chronic obstructive pulmonary disease an echocardiographic and Doppler study. Am J Respir Crit Care Med 2000; 162:670-675.

47 Gan CTJ, Holverda S, Marcus JT, Paulus WJ, Marques KM, Bronzwaer JGF, et al. Right ventricular diastolic dysfunction and the acute effects of sildenafil in pulmonary hypertension patients. Chest 2007; 132:11-17.

48 Abusaid GH, Barbagelata A, Tuero E, Mahmood A, Sharma G. Diastolic dysfunction and COPD exacerbation. Postgrad Med 2009; 121:76-81. 